\title{
Application Of Relevance Maps Method To Evaluate The Suitability Of Coal Samples For Fluidal Gasification Process
}

\author{
Dariusz Jamroz ${ }^{1}$, Tomasz Niedoba ${ }^{2, a}$ and Agnieszka Surowiak ${ }^{2}$ \\ ${ }^{1}$ AGH University of Science and Technology, Faculty of Faculty of Electrical Engineering, Automatics, Computer Science and \\ Biomedical Engineering, Department of Applied Computer Science, al. Mickiewicza 30, 30-059 Kraków, Poland \\ ${ }^{2} \mathrm{AGH}$ University of Science and Technology, Faculty of Mining and Geoengineering, Department of Environmental Engineering \\ and Mineral Processing, al. Mickiewicza 30, 30-059 Kraków, Poland
}

\begin{abstract}
The coal gasification process is one of the technologies which gain more and more attention among technologists dealing with processing and utilization of coal. In case of ground gasification, one of such technologies is fluidized bed gasification. For such gasification the guidelines were elaborated within the scientific project of NCBiR no. 23.23.100.8498/R34 Authors chose main of these guidelines, concerning the required levels of certain coal features. In purpose of investigating coal for its suitability to gasification, samples were collected from two Polish mines: ZG Janina and ZG Wieczorek and processed properly.

The methods being used to visualization of multidimensional data through transformation of multidimensional space into two-dimensional space allow to present multidimensional data on computer screen. Among such methods, relevance maps method can be found which was used in this paper to present and analyze set of seven-dimensional data describing coal samples originating from both mines. It was decided to check whether this method of visualization of multidimensional data allows to divide the samples space into subspaces of various usefulness to the process of fluidal gasification or not. The method enables the visualisation of the optimal subspace containing the set requirements concerning the properties of coals intended for this process.
\end{abstract}

\section{Introduction}

In the paper, coal samples coming from two coal mines Janina Mining Plant (ZG Janina) and Wieczorek Coal Mine (ZG Wieczorek) were analysed. The above mentioned samples were taken in order to evaluate their suitability for on-surface gasification in fluidised bed. The properties of coals directed to gasification must comply with the limits [3, 5-8, 32-33, 40-41], wherein it must be noted that they are linked with each other. The evaluation of coal suitability for gasification should be therefore conducted multidimensionally with the use of multidimensional distributions of properties and their statistics [4, 15-24, 27, 30-31, 35-38, 43-53]. It is a natural thing that the analysis of multidimensional properties and statistics begin with the analysis of particle density distribution and particle size distribution of coals and then is extended on the basis of further coal properties, especially the contents of components and reactions to the processes of its processing. The analysis of coal in terms of distribution of the so-called class-fraction is the initial information on the coal capability of developing the surface area and concentration of flammable and volatile parts and ash. While multidimensional methods of visualisation allow for the combined interpretation of all measured properties in tested terms. Recently, with development of information science, multidimensional statistical analyzes gained significant meaning. It is worthy to mention here multidimensional visualization methods which can be treated as modern analysis tools. Among such types of methods the observational tunnels method can be found], parallel axes method, Kohonen maps, relevance maps, Principal Component Method, multidimensional scaling or autoassociative neural networks. The sources where is possible to find additional information about the applied methodology and similar methods are [1-2, 12-14, 25-26, 28-29, 34, 39, 42, 54].

\section{Data}

In total, from both coal mines, 99 samples (50 from ZG Janina and 49 from ZG Wieczorek were obtained containing such parameters as: total sulfur content, hydrogen content, nitrogen content, chlorine content, total carbon content, heat of combustion and ash content. The card of technological suitability of coal was used additionally [5-6], in which key, relevant and additional parameters, having effect on the gasification process, were described. On the card's basis coal samples, which are subjected to the gasification process in an effective way, were identified. Conditions used are: calorific value $[\mathrm{kJ} / \mathrm{kg}]>18000, \quad$ ash $\quad$ contents $<25 \%$, chlorine contents $<0.1 \%$, total sulfur contents $<2 \%$, elementary carbon contents $>60 \%, 3.5 \% \leq$ hydrogen contents $\leq 5.5 \%$, nitrogen contents $<2 \%$. On the basis of the presented conditions, among the analysed 99 samples only 18 samples were identified as those which can be subject to gasification in an efficient way. Among those 18 samples, 17 came from ZG Janina and only one sample came from ZG Wieczorek.

\footnotetext{
${ }^{\mathrm{a}}$ Corresponding author: tniedoba@agh.edu.pl
} 
Table 1. Elemental analysis of coal in layer II after beneficiation in the jig - ZG Janina

\begin{tabular}{|c|c|c|c|c|c|c|c|}
\hline $\begin{array}{c}\text { Fraction } \\
d[\mathrm{~mm}]\end{array}$ & $\begin{array}{c}\text { Total sulphur } \\
\text { content } \\
\mathbf{S}_{\mathbf{t}^{\mathrm{a}}}[\%]\end{array}$ & $\begin{array}{c}\text { Hydrogen } \\
\text { content } \\
\text { H }^{\mathrm{a}}[\%]\end{array}$ & $\begin{array}{c}\text { Nitrogen } \\
\text { content } \\
\mathrm{N}^{\mathrm{a}}[\%]\end{array}$ & $\begin{array}{c}\text { Chlorine } \\
\text { content } \\
\mathrm{Cl}^{\mathrm{a}}[\%]\end{array}$ & $\begin{array}{c}\text { Total } \\
\text { carbon } \\
\text { content } \\
C^{\text {a }}[\%]\end{array}$ & $\begin{array}{c}\text { Heat of } \\
\text { combustion } \\
Q_{s}{ }^{\mathrm{a}}[\mathrm{kJ} / \mathrm{kg}]\end{array}$ & $\begin{array}{c}\text { Ash } \\
\text { content } \\
A^{\mathrm{a}}[\%]\end{array}$ \\
\hline$<1.00$ & 1.09 & 3.75 & 1.06 & 0.14 & 62.70 & 24727 & 9.20 \\
\hline $1.00-2.00$ & 0.88 & 3.99 & 1.05 & 0.15 & 66.10 & 26074 & 5.10 \\
\hline $2.00-3.15$ & 0.86 & 4.01 & 1.08 & 0.12 & 66.30 & 26116 & 4.70 \\
\hline $3.15-5.00$ & 0.88 & 3.88 & 1.03 & 0.09 & 65.10 & 25785 & 4.80 \\
\hline $5.00-6.30$ & 0.95 & 4.21 & 1.09 & 0.08 & 66.70 & 26489 & 4.80 \\
\hline $6.30-8.00$ & 0.87 & 4.33 & 1.15 & 0.08 & 66.00 & 26380 & 4.80 \\
\hline $8.00-10.00$ & 1.01 & 4.2 & 1.15 & 0.09 & 66.90 & 26486 & 5.00 \\
\hline $10.00-12.50$ & 0.83 & 4.17 & 1.09 & 0.09 & 67.60 & 26633 & 4.70 \\
\hline $12.50-16.00$ & 0.84 & 4.31 & 1.13 & 0.07 & 68.40 & 26771 & 4.90 \\
\hline $16.00-18.00$ & 0.69 & 4.45 & 1.11 & 0.08 & 68.00 & 27267 & 4.70 \\
\hline
\end{tabular}

In order to investigate the mineral beneficiation capability intended for the process of gasification in fluidised bed - bituminous coals from ZG Janina (coal of 31.2 type) and ZG Wieczorek (coal of 32 type) - each of them was subjected to the beneficiation process in the laboratory ring jig ( 10 rings, coal in the class of 0 $18 \mathrm{~mm}$ ). After the completion of the separation process, material was divided into 5 layers (with 2 rings) and each of them was sieved on sieves into 10 particle fractions, establishing yields of layers and fractions. Then, products obtained in such a way - particle fractions, after the separation of analytical samples, were subjected to chemical elemental and technical analysis of coal in order to characterise features influencing gasification processes. Table 1 presents an example of the obtained data for layer II from ZG Janina.

\section{Relevance maps}

\subsection{Description of the method}

Relevance maps method on plane serving for data visualization is based on placing special points called relevance points which represent individual features of considered object [22, 29, 44]. For each feature (coordinate) the relevance point representing this feature is assigned. That means that by seven-dimensional data set 7 such points are placed on plane which represent individual coordinates. The distribution of the points representing presented multidimensional data shows relations between these data and features. The more $i^{\text {th }}$ feature is present in certain object (what means that $i^{\text {th }}$ coordinate is higher) the closest point representing certain object according to relevance point representing $i^{\text {th }}$ feature (coordinate) should be. In this way each relevance point representing certain feature divides plane on areas more or less dependent on $i^{\text {th }}$ feature (more or less distanced from relevance point representing $i^{\text {th }}$ feature).

\subsection{Algorithm}

Set of initial data compounds of elements described by $\mathrm{n}$ features. It can be then treated as set of $n$-dimensional vectors. Let mark $i^{\text {th }}$ initial data vector as $x_{i}=\left(x_{i, 1}, x_{i, 2}, \ldots\right.$ $x_{i, n}$ ). Algorithm serving to realize visualization by means of relevance map consists several steps, which are:

- Scaling of initial data. Individual features, represented by individual data dimensions are scaled in the way assuring their fitness to the same specific range. It was decided to scale the individual coordinates (features) of data set vectors to range $(0,1)$.

- Randomization of initial location of points images in 2-dimensional space. Let assume that image of $j^{\text {th }}$ point $x_{j}$, what means the point related to it in 2-dimensional space, will be marked as $p_{j}=\left(u_{j}, v_{j}\right)$. In previous point each of data vectors coordinates was scaled to range $(0,1)$. That is why the initial coordinates $u_{j}$ and $v_{j}$ were drawn also from range $(0,1)$ by plate probabilistic distribution applied.

- Randomization of initial location of relevance points in 2-dimensional space. For $n$-dimensional data $\mathrm{n}$ such points are created. These points will be marked as $w_{i}=\left(y_{i}, z_{i}\right)$. Initial coordinates $y_{i}$ and $z_{i}$ are drawn also from range $(0,1)$ by means of application of plate probabilistic distribution.

Next steps are realized for each initial data vector:

- For certain $j^{\text {th }}$ vector of data $x_{j}$ the distance of its image $p_{j}$ from each relevance point $w_{i}$ is calculated by means of Euclidean metrics:

$$
D_{i j}=\sqrt{\left(y_{i}-u_{j}\right)^{2}+\left(z_{i}-v_{j}\right)^{2}}
$$

- The location of image $p_{j}$ is changed taking into consideration distance from each relevance point $w_{i}$. It is changed in the way assuring the distance $D_{i j}$ from relevance point $w_{i}$ 
to be relevant to $i^{\text {ith }}$ coordinate of data vector $x_{j}$. The goal is to achieve such image $p_{j}$ which by high value of $i^{\text {th }}$ coordinate of point $x_{j}$ (close to 1 ) is possibly close to relevance point $w_{i}$. For small value of $i^{\text {th }}$ coordinate of point $x_{j}$ its image $p_{j}$ is far from relevance point $w_{i}$ :

$$
\begin{aligned}
& \tilde{u}_{j}=u_{j}+0.01 \frac{\left(u_{j}-y_{i}\right)\left(1-x_{j, i}-D_{i j}\right)}{D_{i j}} \\
& \tilde{v}_{j}=v_{j}+0.01 \frac{\left(v_{j}-z_{i}\right)\left(1-x_{j, i}-D_{i j}\right)}{D_{i j}}
\end{aligned}
$$

where $\tilde{u}$ and $\widetilde{v}$ are values after change. Equations (2) and (3) cause that point $p_{j}$ is closer to point $w_{i}$ when $D_{i j}>$ $1-x_{j, i}$ and farther from $w_{i}$ when $D_{i j}<1-x_{j, i}$. The dislocation of point $p_{j}$ occurs according to straight line crossing through points $p_{j}$ and $w_{i}$. Constant value 0.01 means the speed of points moving in proper directions.

Next steps are realized for each relevance point:

- For given $i^{\text {th }}$ relevance point its distance $D_{i j}$ is calculated from each image $p_{j}$ of data vector by means of equation (1).

- The location of relevance point $w_{i}$ is changed taking into consideration distance from each image $p_{j}$ of data vector $x_{j}$. It is changed in the way assuring distance $D_{i j}$ from relevance point $w_{i}$ to be relevant to $i^{\text {th }}$ coordinate of data vector $x_{j}$. Similarly like in step 5 the goal is to obtain possibly closest location of image $p_{j}$ to relevance point $w_{i}$ by high value of $i^{\text {th }}$ coordinate of point $x_{j}$ (close to 1 ). For small value of $i^{\text {th }}$ coordinate of point $x_{j}$ its image $p_{j}$ is far from relevance point $w_{i}$ :

$$
\begin{aligned}
& \widetilde{y}_{i}=y_{i}+0.01 \frac{\left(y_{i}-u_{j}\right)\left(1-x_{j, i}-D_{i j}\right)}{D_{i j}} \\
& \widetilde{z}_{i}=z_{i}+0.01 \frac{\left(z_{i}-v_{j}\right)\left(1-x_{j, i}-D_{i j}\right)}{D_{i j}}
\end{aligned}
$$

where $\tilde{y}$ and $\widetilde{z}$ are values after change. Equations (4) and (5) cause that relevance point $w_{i}$ is closer to point $p_{j}$ when $D_{i j}>1-x_{j, i}$ and farther from it when $D_{i j}<1-x_{j, i}$. Disslocation of relevance point $w_{i}$ occur according to straight line crossing through points $p_{j}$ and $w_{i}$. The constant value 0.01 means speed of points moving in proper directions.

The whole procedure covered in steps 4-7 is repeated ITER times (where ITER means the parameter accepted in certain moment).

In this way the image of multidimensional initial data points in two-dimensional space were obtained. It is sufficient then to present image of each vector on computer screen. It is realized by drawing symbol representing fraction to which data vector $x_{i}$ is related in place of coordinates $\left(u_{j}, v_{j}\right)$. Additionally, symbols representing relevance points in in screen location $\left(y_{i}, z_{i}\right)$ can be drawn. In this way the image of multidimensional points is created on computer screen.

\section{Experimental results}

In purpose of visualization of seven-dimensional data describing coal samples the computer program was constructed which was based on assumptions presented in previous part of the paper. It was written in $\mathrm{C}++$ language by means of Microsoft Visual Studio software. The obtained results were presented on Figs. 1-4. These views show how seven-dimensional data are transformed by means of relevance maps to just two dimensions. The algorithm of visualization by means of relevance map works in the way ensuring that despite significant reduction of dimensions number the distances between point representing certain data vector and relevance points depend possibly the most on coordinates of this data vector. In such way the important features of seven-dimensional data can be seen on computer screen.

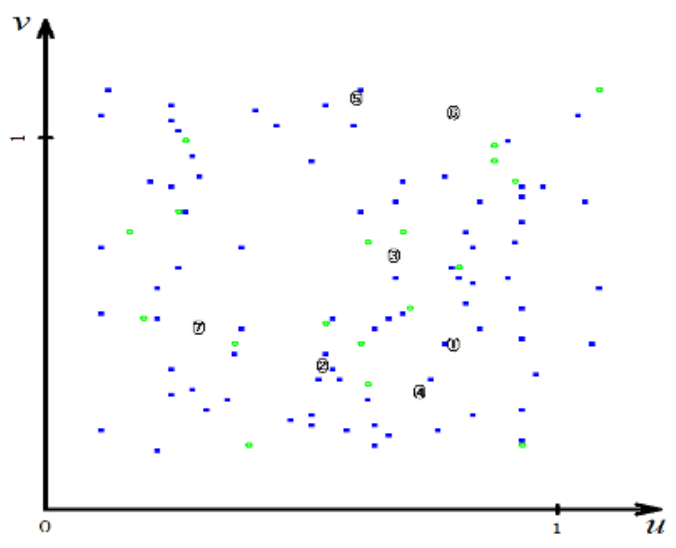

Figure 1. Initial position, in which each image of point representing seven-dimensional coal samples and each relevance point are in random positions. By ( - ) the images of point representing coal samples less suitable to fluidal gasification were marked, (o) - samples well suitable to fluidal gasification. Digit of the value $i$ means relevance point representing $i^{\text {th }}$ coordinate.

It was decided to check whether the method of relevance maps of data visualization allows to divide samples space into areas of various suitability for on-surface fluidal gasification process. Figures 1-4 present views of the points representing seven-dimensional data vectors describing coal samples obtained from ZG Janina and ZG Wieczorek. It is visible on Figs. 1-3 how the grouping of points representing discussed data according to the division on samples of well suitable and less suitable coals occur with the growth of ITER parameter. It can be seen that point being images of the data representing the same coal fractions start to gather in separated subareas and start to group. The clearness of the space division grows with the growth of ITER parameter what means better fitting of the distance $D_{i j}$ between points images and relevance points in two-dimensional space and related coordinates of seven-dimensional data vector $x_{j}$. Figure 1 shows the initial position in which each image of entry data point 
and each relevance point is located in random position on the screen. Figure 2 presents that even by small value of the ITER parameter being equal to 100 , the images of points representing the same fractions start to group. Figure 3 shows the most clear result which was obtained for the discussed data according to the division of samples into well and less suitable coals to gasification process. It occurred by the value of ITER parameter being equal to 2025. It can be visible on this screen that images of points representing samples of well and less suitable coals to gasification are located in separated subareas and gather in groups. Also, it can be seen that these gatherings on the whole picture can be easily separated. That means that through application of the relevance maps method is possible to divide samples space on the areas of various suitability for fluidal gasification process. Then, this method allows to qualify other, unknown samples of coals into well or less suitable for gasification ones through the visualization process. It is important mainly because samples of well suitable coal gather inside of the seven-dimensional cuboid - what is a simplification. It occurs directly from the fact that the accepted conditions determining affiliation to this group ("Card of technological suitability of coal") are simple inequalities by which means is easily to verify such affiliation. In reality however, it can occur that the affiliation area can have much more complicated shape. In such case, on the basis of larger amount of samples which would be empirically affiliated to the well suitable for gasification ones, the method of relevance maps allows to try to get the division of space into areas representing samples of coals well and less suitable to gasification process. In this way, it can occur that the obtained mapping will more precisely image the reality. That is why the previous statement that relevance maps method allows to divide the samples space into areas of various suitability to fluidal gasification process becomes particularly important.

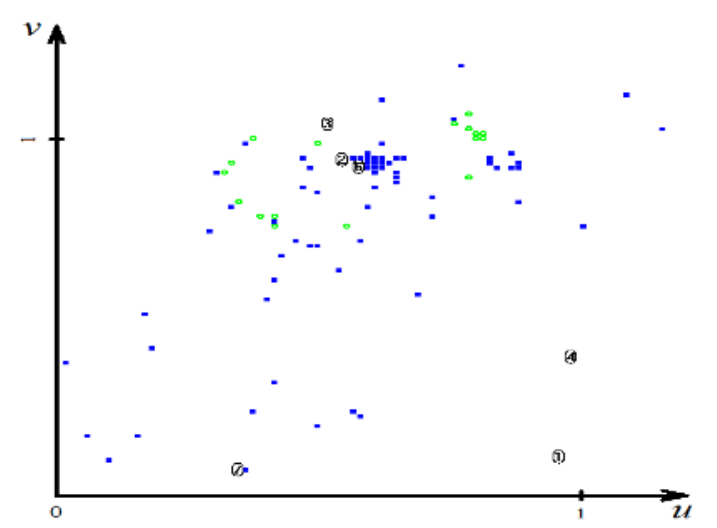

Figure 2. View of seven-dimensional data representing coal samples of various suitability to fluidal gasification process by the value of ITER parameter being equal to 100 . Starting of grouping is visible. By $(\boldsymbol{\square})$ the images of point representing coal samples less suitable to fluidal gasification were marked, (o) samples well suitable to fluidal gasification. Digit of the value $i$ means relevance point representing $i^{\text {th }}$ coordinate.

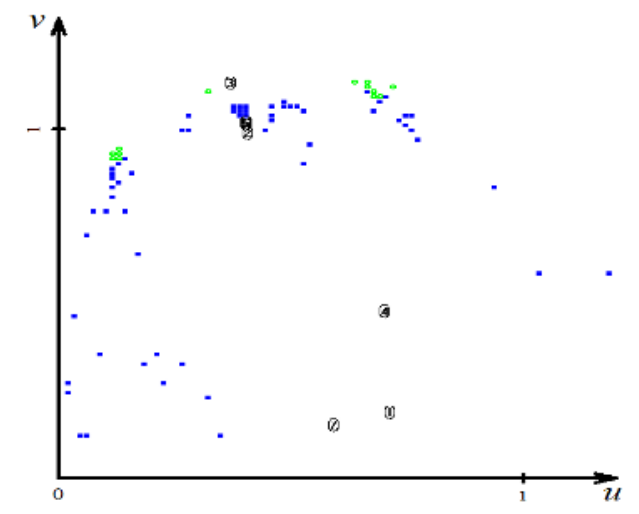

Figure 3. The most clear obtained view of seven-dimensional data representing coal samples of various suitability to fluidal gasification process by the value of ITER parameter being equal to 2025. By ( $\boldsymbol{\square})$ the images of point representing coal samples less suitable to fluidal gasification were marked, (o) - samples well suitable to fluidal gasification. Digit of the value $i$ means relevance point representing $i^{\text {th }}$ coordinate.

Figure 4 presents the view of the discussed data according to completely new sort division - on samples of coals originating from ZG Janina and ZG Wieczorek. It can be seen clearly that the images of the points representing samples of coals from different mines are located in separated subareas and form gatherings. Furthermore, these gatherings can be easily separated on the picture. On the basis of this Figure it can be stated that the method of relevance maps allows to divide space on areas being characteristic for various mines. Thanks to this fact is possible to apply it to analyze new, unknown samples and through their visualization to qualify them according to their origin to the appropriate group.

It should be noticed that the algorithm of relevance maps method does not use the information of affiliation of points representing data to certain fractions. In this situation this how images of points representing certain fraction will be grouped depends only on some data properties noticed by the algorithm. That is why Figs 3 and 4 differ between themselves only by affiliation of individual points to various fractions. It occurs from the fact that both Figures were created as the result of work of relevance maps algorithm on precisely the same sevendimensional data and by the same value of ITER parameter being equal to 2025 (with omitted information of point affiliation to individual fractions). That is why the location of points on Figs 3 and 4 is identical - only the assignment of individual points to appropriate fractions is different. 


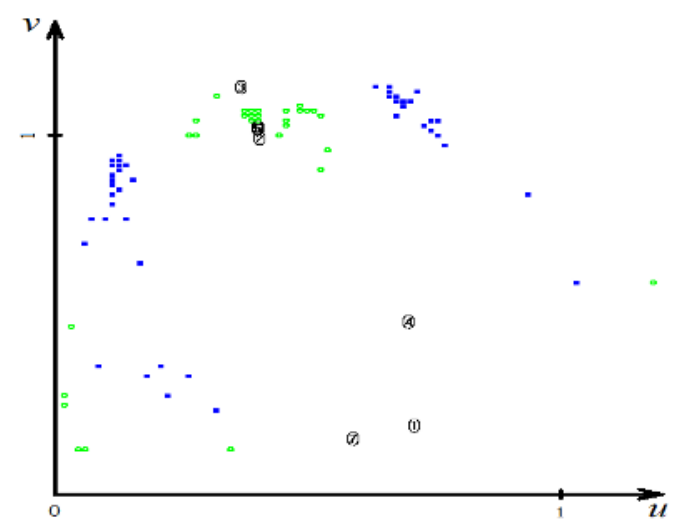

Figure 4. View of seven-dimensional data with division into extraction points by the value of ITER parameter being equal to 2025. By (ש) the images of points representing coal samples obtained in ZG Janina were marked, by (o) - samples of coal obtained in ZG Wieczorek. Digit of the value $i$ means relevance point representing $i^{\text {th }}$ coordinate.

\section{Conclusions}

The conducted experiments based on visualization of seven-dimensional data by means of relevance maps methods allow to conclude that:

- Multidimensional visualization by means of relevance maps allow to state that the images of points representing samples of coal well or less suitable coals are located in separated subareas and form gatherings which can be easily separated. The relevance maps method allow then to divide the samples space on areas of various suitability to fluidal gasification process. It is possible then to qualify coals to groups of well suitable or less suitable for gasification.

- As a result of visualization applying relevance maps method is possible to state that images of points representing coal samples from ZG Janina and ZG Wieczorek are located in separated subareas and form gatherings which can be easily separated. It is possible then to divide samples space into areas representing various mines and to identify origin of the coals (ZG Janina or ZG Wieczorek) by means of relevance maps.

- The algorithm of visualization by means of relevance maps does not use the information about the affiliation of points representing data to certain fractions. In such situation this how images of points representing certain fraction will be grouped depends only on some data properties noticed by the algorithm. This is done independently on their affiliation to individual fractions.

- The same division of samples space conducted by means of relevance maps method groups points representing analyzed data according to their origin (point of extraction - ZG Janina or ZG Wieczorek) and also their suitability for fluidal gasification process.

- On the basis of "Card of technological suitability of coal", among analyzed 99 samples of coals only 18 of them were marked as the ones which gasify efficiently. Among these 18 samples, 17 originated from ZG Janina and only one from ZG Wieczorek.

- Clearness of the results grows with more precise fitting of the distance $D_{i j}$ between points images and their relevance points in two-dimensional space and appropriate coordinated of seven-dimensional data vector $x_{j}$ (with the growth of the value of ITER parameter).

- Clearness of obtained results depends highly on accepted parameters.

- A problem occurring by such visualization is necessity of selection of the parameters in purpose of getting view which clearly presents information searched by the researcher. It should be mention that during conducted experiments the views were obtained by the value of ITER parameter from 1 to 2000 . The experiments were conducted multiple times by renewed generating of random initial values. Sometimes it lead to obtain more clear results. Also, various speeds of learning were assumed before the one presented in equations 3 and 4 was accepted. The presented results are the clearest ones from the obtained ones.

\section{Acknowledgement}

The paper is an effect of the statutory project no. 11.11.100.276.

\section{References}

1. A. Glowacz, Measurement Science Review 15(4), 167-175 (2015)

2. A. Inselberg, Parallel Coordinates: VISUAL Multidimensional Geometry and its Applications (Springer, 2009)

3. A. Kosminski, D.P. Ross, J.B. Agnew, Fuel Processing Technology 87(11), 943-952 (2006)

4. A. Nowak, A. Surowiak, Archives of Mining Sciences 58(4), 1209-1220 (2013)

5. A. Sobolewski, T. Chmielniak, T. Topolnicka, G. Swieca, Polish Mining Review 2, 174-183 (2012) [in Polish]

6. A. Sobolewski, T. Chmielniak, T. Topolnicka, N. Gieza, Karbo 1, 28-38 (2013) [in Polish]

7. A. Strugala A., G. Czerski, Chemical Review 91(11), 2181-2185 (2012) [in Polish]

8. A. Strugala, K. Czalicka-Kolarz, M. Sciazko, Energy Policy Journal 14(2), 375-390 (2011)

9. A. Surowiak, M. Brozek, Physicochemical Problems of Mineral Processing 52(1), 228-243 (2016)

10. A. Surowiak, M. Brozek, Archives of Mining Sciences 59(2), 553-562 (2014)

11. A. Surowiak, M. Brozek, Archives of Mining Sciences 59(1), 269-282 (2014)

12. A.K. Jain, J. Mao, In: Proc. IEEE Internat. Joint Conf. On Neural Networks (Baltimore, MD, 3, 335340, 1992)

13. C. Aldrich, Pattern Recognition Letters 19(8), 749764 (1998) 
14. D. Asimov, SIAM Journal of Scientific and Statistical Computing 6, 128-143 (1985)

15. D. Foszcz, M. Duchnowska, T. Niedoba, T. Tumidajski, Physicochemical Problems of Mineral Processing 52(1), 98-111 (2016)

16. D. Jamroz, Archives of Mining Sciences 59(2), 413425 (2014a)

17. D. Jamroz, In: Gruca A., Czachórski T., Kozielski S. (eds.), Man-Machine, Interactions 3 (AISC, Switzerland, Springer International Publishing, 242, 443-450, 2014b)

18. D. Jamroz, Physicochemical Problems of Mineral Processing 50(2), 719-734 (2014c)

19. D. Jamroz, In: Cyran K., Kozielski S., Peters J., Stanczyk U., Wakulicz-Deja A. (eds.), ManMachine, Interactions, (AISC, Heidelberg, SpringerVerlag, 59, 445-450, 2009)

20. D. Jamroz, T. Niedoba, Archives of Mining Sciences 60, 1, 39-50 (2015)

21. D. Jamroz, T. Niedoba, Physicochemical Problems of Mineral Processing 50(1), 185-202 (2014)

22. D. Jamroz, T. Niedoba, Physicochemical Problems of Mineral Processing 51(2), 769-784 (2015)

23. D. Saramak, Physicochemical Problems of Mineral Processing 49(1), 495-512 (2013)

24. D. Saramak, Archives of Mining Sciences, 56, 3, 517-526 (2011)

25. G.J. Lyman, Coal Preparation 13, 179-195 (1993)

26. H. Hotelling, Journal of Educational Psychology 24, 417-441 and 498-520 (1933)

27. H.A.M. Ahmed, J. Drzymala, Physicochemical Problems of Mineral Processing, 39, 129-139 (2005)

28. I.T. Jolliffe, Principal Component Analysis (Series: Springer Series in Statistics, Springer, NY, 2002)

29. J. Assa, D. Cohen-Or, T. Milo, Visual Computer 15(5), 217-234. (1999)

30. J. Drzymala, Basics of minerallurgy (Oficyna Wydawnicza Politechniki Wrocławskiej, 2009) (in Polish)

31. J. Drzymala, Mineral processing: foundations of theory and practice of minerallurgy (Oficyna Wydawnicza Politechniki Wrocławskiej, Wroclaw, 2007)

32. J. Marciniak-Kowalska et al. Project report NCBiR, Elaboration of technology of coal gasification for highly efficient fuel and energy production, report from part of the project Investigations of coal beneficiation by means of mechanical processing, (not published work, 2012-13) [in Polish]

33. J. Marciniak-Kowalska, T. Niedoba, A. Surowiak, T. Tumidajski, Archives of Mining Sciences 59( 3), 677-690 (2014)
34. J.B. Kruskal, Psychometrika 29, 1-27 (1964)

35. M. Brozek, A. Surowiak, A. Jarosinski, Archives of Metallurgy and Materials 60( 3), 1737-1744 (2015)

36. M. Brozek, A. Surowiak, Archives of Mining Sciences 55, 21-40 (2010)

37. M. Brozek, A. Surowiak, Physicochemical Problems of Mineral Processing 41, 397-413 (2007)

38. M. Brozek, A. Surowiak, Physicochemical Problems of Mineral Processing 39, 199-210 (2005)

39. R. Snopkowski, A. Napieraj, Archives of Mining Sciences 57(1), 121-138 (2012)

40. T. Borowiecki, J. Kijenski, J. Mochnikowski, M. Sciazko M. (ed.), Pure energy, chemical products and coal made fuels - evaluation of development potential (IChPW, Zabrze, 2008) [in Polish]

41. T. Chmielniak, G. Tomaszewicz, Karbo 3, 191-201 (2012) [in Polish]

42. T. Kohonen, Self Organization and Associative Memory (Springer-Verlag, 1989)

43. T. Niedoba, A. Surowiak, Proceedings of the XXVI International Mineral Processing Congress, New Delhi 1, 3844-3854 (2012)

44. T. Niedoba, Archives of Mining Sciences 60(1), 93$106(2015)$

45. T. Niedoba, D. Jamroz, Archives of Mining Sciences 58(4), 1317-1333 (2013)

46. T. Niedoba, Multidimensional characteristics of random variables in description of grained materials and their separation processes, (Wydawnictwo Instytutu Gospodarki Surowcami Mineralnymi i Energią PAN, Krakow, 2013a) [in Polish].

47. T. Niedoba, AGH Journal of Mining and Geoengineering 33(4), 235-244 (2009) [in Polish].

48. T. Niedoba, Physicochemical Problems of Mineral Processing 50(2), 575-589 (2014)

49. T. Niedoba, Physicochemical Problems of Mineral Processing 49(1), 175-188 (2013b)

50. T. Niedoba, in Proceedings of the XIV Balkan Mineral Processing Congress (Tuzla, Bosnia and Herzegovina, 57-59, 2011)

51. T. Olejnik, A. Surowiak, T. Gawenda, T. Niedoba, T. Tumidajski, AGH Journal of Mining and Geoengineering 34(4/1), 207-216 (2010) [in Polish]

52. T. Tumidajski, D. Saramak, Methods and models of mathematical statistics in mineral processing, (Wydawnictwo AGH, Krakow, 2009) [in Polish]

53. T. Tumidajski, Stochastic analysis of grained materials properties and their separation processes, (Wydawnictwo AGH, Krakow, 1997) [in Polish]

54. W.S. Cleveland, R. McGill, Journal of the American Statistical Association 79, 807-822 (1984) 